\title{
MACRO/MICROPOLÍTICA, COTIDIANO ESCOLAR E CONSTITUIÇÃO DE UM CORPO COLETIVO EM DEVIR
}

\author{
MACRO/MICRO-POLITICS, SCHOOL EVERYDAY AND THE CONSTITUTION \\ OF A COLLECTIVE BODY IN BECOMING
}

\author{
MACRO/MICROPOLITICA, COTIDIANO ESCOLAR Y CONSTITUCIÓN DE UN \\ CUERPO COLECTIVO EM DEVENIR
}

Janete Magalhães Carvalho ${ }^{1}$

\begin{abstract}
RESUMO
Objetiva problematizar as relações de poder que, macro e micropoliticamente, atuam nos corpos coletivos potencializando uma vida em composição com forças heterogêneas no plano de imanência dos cotidianos escolares. Busca argumentar sobre os lugares, os espaços e a ordem institucional que tomam corpo e possibilitam a constituição de coletivos articulados como políticas ativas, assim como, questionar os conceitos e as práticas a partir das quais os corpos que habitam e/ou atravessam os cotidianos escolares são qualificados, passando pelas forças e fluxos que os modelam ou os criam. Usa como abordagem metodológica redes de conversações derivadas de pesquisa no cotidiano escolar com professores de quatro escolas de ensino fundamental do município de Vitória/ES, cujas falas se apresentam, entremeadas ao texto, como devires-afetivos de corpos coletivos, problematizando e potencializando uma vida em composição com forças heterogêneas no plano de imanência dos cotidianos escolares.
\end{abstract}

PALAVRAS-CHAVE: Corpo. Macro/Micropolítica. Cotidiano escolar. Coletivo. Afetos.

\begin{abstract}
Aims to problematize the relations of power that, macro and micropolitically, act in the collective bodies potentializing a life in composition with heterogeneous forces in the plane of immanence of the school everyday life. Search argue about the places, spaces and the institutional order taking body and enable the creation of articulated collective as active policies, as well as to question the concepts and practices from which the bodies they inhabit and/or go through school everyday are qualified, passing by the forces and flows that shape or create them. It uses as a methodological approach networks of conversations derived from research in the school everyday life with teachers from four elementary schools in the city of Vitória/ES, whose statements are presented interspersed with the text, as becoming-affectives of collective bodies, problematizing and potentiating a life in composition with heterogenous forces in the plane of immanence of the school everyday.
\end{abstract}

KEYWORDS: Body. Macro/Micro-politics. Everydayschool. Collective. Affections.

\section{RESUMEN}

Objetiva problematizar las relaciones de poder que, macro y micropoliticamente, actúan en los cuerpos colectivos potenciando una vida en composición con fuerzas heterogéneas en el plano de immanencia de los cotidianos escolares. Se busca argumentar sobre los lugares, los espacios y el orden institucional que toman cuerpo y posibilitan la constitución de colectivos articulados como políticas activas, así como cuestionarlos conceptos y las prácticas a partir de las cuales los cuerpos que habitan y/o atraviesan los cotidianos escolares son calificados, pasando por las fuerzas y flujos que los modelan o los crean. Se utiliza

\footnotetext{
${ }^{1}$ Doutora em Educação - Universidade Federal do Rio de Janeiro (UFRJ) - Rio de Janeiro, RJ - Brasil. Professora do Programa de Pós-Graduação em Educação - Universidade Federal do Espírito Santo (UFES) - Vitória, ES - Brasil. E-mail: janetemc@terra.com.br
}

Submetido em: 24/10/2017 - Aceito em: 18/05/2018

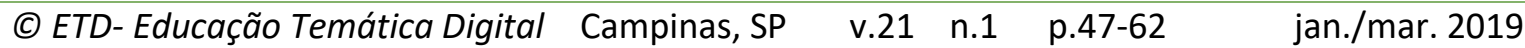


como enfoque metodológico redes de conversaciones derivadas de investigación en el cotidiano escolar com profesores de cuatro escuelas de enseñanza fundamental del municipio de Vitória/ES, cuyas palabras se presentan, entremezcladas al texto, como devires-afectivos de cuerpos colectivos, problematizando y potenciando una vida en composición con fuerzas heterogéneas en el plano de immanencia de los cotidianos escolares.

PALABRAS CLAVE: Cuerpo. Macro/Micropolitica. Cotidiano escolar. Colectivo. Afectos.

\section{COMEÇANDO... MACRO OU MICROPOLÍTICA?}

[...] há nomes que eu acho que estão desencostados...- Por exemplo? - Caso do beija-flor. É um nome que deveria ser consertado. A flor é que levaria o título de beija-pássaros (MIA COUTO, 2014).

Tal qual o beija-flor, pássaro, e a flor, atravessados por linhas existenciais que os enquadram em linhas molares, moleculares e de fuga, a configuração de um cotidiano escolar e de seus dispositivos não nos é dada de imediato. Necessário se faz cartografar as linhas de um dispositivo, ${ }^{2}$ entrando nelas (nas linhas) e se deixando atravessar por elas para tentar ver o que habita e compõe a vida escolar.

De modo geral, as diferentes linhas de dispositivos se repartem em dois grupos: as linhas de estratificação ou de sedimentação (molares) e as linhas de atualização e de criatividade (moleculares, de fuga e...). Ao primeiro tipo corresponderia uma segmentaridade dura referente aos papéis modelados, como família, profissão, consumo etc. Segmentos bem determinados, em todas as direções, que nos enquadrariam em todos os sentidos, como "[...] pacotes de linhas segmentarizadas" (DELEUZE; PARNET, 2004, p. 145). Juntamente com essas linhas duras, temos linhas moleculares bem mais flexíveis que nos atravessariam não apenas como indivíduos, mas também como sociedade e grupos. Segundo Deleuze e Parnet (2004), sob essa segunda espécie de linhas, de fluxos moleculares, passariam devires, microdevires, que não teriam o mesmo ritmo das linhas duras. São, porém, linhas entrelaçadas e intercambiantes tal qual o pássaro-flor ou a flor-pássaro.

Para Deleuze e Guattari (1997), não há oposição entre molar-molecular e macromicro. Tanto o molecular como processo pode nascer no macro, como o molar pode se instaurar no micro. Assim, não há lógica de contradição entre os níveis molar e molecular, pois esses mesmos tipos de componentes estão em jogo num determinado espaço social e podem funcionar em nível molar, de modo emancipador e, coextensivamente, em nível molecular, reacionários ou microfascistas. Os problemas se colocam sempre e, ao mesmo tempo, nos dois níveis. "A questão micropolítica é a de

\footnotetext{
${ }^{2}$ De acordo com Deleuze (1988, p. 44), um dispositivo é “[...] uma máquina abstrata, definindo-se por meio de funções e matérias informes, ele ignora toda a distinção de forma entre um conteúdo e uma expressão, entre uma formação discursiva e uma não-discursiva. É uma máquina quase muda e cega, embora seja ela que faça ver e falar".
} 
como reproduzimos (ou não) os modos de subjetividade dominante" (GUATTARI; ROLNIK, 1986, p. 133).

Sendo assim, este artigo tem como objetivo problematizar as relações de poder que, macro e micropoliticamente, atuam nos corpos coletivos potencializando uma vida em composição com forças heterogêneas no plano de imanência dos cotidianos escolares. Nesse sentido, busca argumentar sobre os lugares, os espaços e a ordem institucional que nos cotidianos escolares ganham expressão e possibilitam a constituição de coletivos articulados como políticas ativas. Também discute as categorias a partir das quais os corpos que habitam e/ou atravessam os espaços da escola são qualificados, passando pelas forças e fluxos que os modelam ou os criam.

Explicitar, problematizar e superar as limitações desses cotidianos escolares, como corpos coletivos, orienta as práticas discursivas apresentadas nos entremeios de nossa argumentação como condição de sua potência de vida - a vitalidade propriamente dita desta escritatexto. Dessa vitalidade emana o poder que terá uma proposta de ativar a sensibilidade ao concentrado de forças que ela presentifica na subjetividade daqueles que a vivem; e, por extensão, ativar a sensibilidade das forças que transbordam a cartografia vigente em seu entorno e exigem um trabalho de criação que redesenhe seus contornos.

Desse modo, as conversas apresentadas no texto são produções derivadas de pesquisa ${ }^{3}$ mais ampla, com professores de quatro escolas de ensino fundamental do município de Vitória/ES, cujo enfoque metodológico buscou examinar a potência das redes de conversações na constituição das relações praticaspolíticas que articulam a constituição do comum nos currículos, nos processos de aprender, na formação de professores, entendendo que todas as práticas são políticas e imersas em redes de conversações como formas de dizer de nossas experiências. O critério para seleção das escolas foi o da adesão ou interesse em participar dos grupos a serem estabelecidos com os professores. As conversações realizadas em encontros quinzenais com os docentes foram gravadas, transcritas e associadas aos registros realizados durante as conversações informais entre pesquisadores e professores. ${ }^{4}$

Nesse aporte metodológico, as conversações são tomadas para além do processo de individualização, ou seja, concebidas como agenciamentos em redes de conversações (CARVALHO, 2009) que potencializam acontecimentos inscritos em modos coletivos. Denominamos coletivo o plano que permite superar a dicotomia indivíduosociedade, tomando coletivo, não como totalização, mas como agenciamento: “[...] a

\footnotetext{
${ }^{3}$ Pesquisa desenvolvida no período 2013-2016, com apoio do CNPq, denominada "Currículo e formação de professores: devir-docência como afirmação da potência de aprendizagem em composições curriculares".

${ }^{4}$ Apresentamos neste artigo o registro de algumas das conversações, considerando os objetivos da análise nele engendrados.
} 
relação, entendida como agenciamento, é o modo de funcionamento de um plano coletivo, que surge como plano de criação, de co-engendramento dos seres" (ESCOSSIA; KASTRUP, 2005, p. 303). Coletivo como multiplicidade, para além do indivíduo, aquém da pessoa, "[...] junto a intensidades pré-verbais, derivando de uma lógica dos afetos mais do que de uma lógica de conjuntos bem circunscritos" (p. 303).

Ao focarmos as conversações como praticaspolíticas, estamos entendendo política como um modo de atividade humana que coloca sujeitos em relação, articulando-os entre si, segundo padrões e normas não necessariamente jurídicos ou relacionados com um marco legal-institucional. Isso porque a política se faz, também, e de forma intensa, por microrrelações, tal como na micropolítica de Deleuze e Guattari (1997). Desse modo, o caso individual, visto que envolto em processos de individuação, nunca expressa uma forma, mas, sim, o formigamento de muitas intralutas que revelam a densidade política da realidade do caso e do espaçotempo que habita, podendo-se fazer o desdobramento de um caso na direção do plano coletivo das conversações.

Esse plano e/ou face coletiva se orienta pela necessidade de afirmação de um processo inventivo de constituição micropolítica - singularização no plano de imanência do cotidiano escolar em sua relação com outros múltiplos contextos cotidianos - que é produzida pela condição de que os corpos possam colocar suas problematizações. Ou seja, visto que toda aprendizagem se refere ao movimento do pensamento e ao direito de colocar problemas, a metodologia de redes de conversações toma como imprescindível investir na cartografia dos problemas que estão sendo engendrados no plano de imanência em que a pesquisa se desenrolou.

\section{MICROPOLÍTICA, COTIDIANO E RELAÇÕES DE FORÇAS}

Queria tocar um lugar. Mas um lugar me toca. Não é um corpo que toquei ou qualquer outro corpo específico desse espaço, pois há, em torno de um corpo e de variados corpos, um universo intocável, que vive no entre, na relação entre coisas entre salas de aula e recreios, entre um professor e um aluno, entre alunos, entre celulares e dedos ávidos por conexão, entre... - que podemos perceber mesmo temporariamente. São forças que conectam partículas para constituir um grupo, um bando, uma matilha, um estar isolado, e são outras forças que fazem ver um corpo.

O corpo humano, segundo Espinosa (2007), é um indivíduo extremamente complexo, composto de vários corpos, cada um dos quais, também, muito composto. Graças a essa complexidade, ele é apto a afetar e ser afetado de diversas maneiras pelos corpos exteriores, sendo capaz de reter essas afecções, isto é, as modificações nele causadas por essas interações.

De acordo com Espinosa (2007), os corpos complexos são produzidos pela integração de corpúsculos simplíssimos, segundo diferentes proporções de movimento 
e repouso, por isso são indivíduos concretos que se definem como conatus, ${ }^{5}$ o qual, além de pressupor um sistema de movimento e de repouso individual interno e sua relação com o exterior, supõe, sobretudo, o corpo como singularidade complexa. Isso determinará a capacidade de cada conatus para relacionar-se com a pressão externa, produzida por outros corpos tão complexos quanto o seu.

A relação do indivíduo consigo, assim como com os corpos exteriores, jamais será simples, mas múltipla e diversificada. Na visão de Espinosa (2007), pelo conatus, como esforço e/ou potência de agir, os indivíduos se definem pela variação incessante de suas proporções internas de movimento e repouso, ou variação de sua força interna para a conservação, de sorte que o esforço de autoconservação visa a manter a proporção interna no embate com as forças externas, pois são elas que podem destruí-los, como também são elas que os auxiliam a regenerar-se e a crescer.

A relação é plural com o mundo externo. A pele é limite que separa o homem do mundo que o cerca, mas vivemos dessa troca. Quanto mais amplo seus modos de agir, quanto mais complexos os movimentos maiores serão suas afecções. Por ser muito complexo, o corpo humano é capaz de muitas coisas. Por ser composto por várias partes, ele é capaz de ser afetado e de agir de muitas formas. O corpo é um leque de possibilidades. Tais possibilidades múltiplas estão, na atualidade, anestesiadas. Os corpos tendem à passividade e/ou aos afetos tristes e, sendo assim, torna-se urgente, no cotidiano escolar, ampliar a pergunta de Espinosa (2007) sobre o que pode um corpo: o que pode o meu, o teu, mas, principalmente, o nosso corpo? Quais sensações experimentamos visto que mexemos tanto com nosso corpo? Ou será que já vivenciamos o bastante? Experimentamos sozinhos ou no coletivo? Compomos com outros corpos uma vida coletiva?

Junto com objetos e sujeitos, há um plano de forças, de relações que compõem o real social de modo aparentemente tão verdadeiro quanto o espaçotempo que nos toca, mas tão mutável quanto a nossa percepção em relação a ele. O que toca são forças. Sempre há um conjunto de forças agindo em um lugar e o transformando a cada instante.

Como diz Saramago (1997, p. 1), "O destino dos lugares é como uma carta fechada à espera do gesto único que um dia a dará a conhecer". São redes tecidas por forças em relação que atravessam o cotidiano e/ou o plano de imanência e composição entre corpos que habitam o cotidiano escolar e que se tocam, afetando-se em encontros que aumentam ou diminuem a potência de agir. Sendo assim, para nós, a dimensão

\footnotetext{
${ }^{5}$ Termo latino que significa esforço. Para Espinosa (2007, p. 293): “Proposição 25[...]. Demonstração: O esforço pelo qual cada coisa se esforça por perseverar em seu ser é definido exclusivamente pela essência da própria coisa (pela Prop. 7). E exclusivamente dessa dada essência, e não da essência de outra coisa, segue-se (pela Prop. 6 ) necessariamente que cada um se esforça para conservar o seu ser".
} 
micropolítica desses processos se dá no plano de imanência do cotidiano escolar e para além dele. Na conversação entre professores, abaixo, transparece essa dimensão:

-Eu estava com os meninos na sala de aula e eles estavam falando muito. 0 conteúdo enfocava a questão da sexualidade. E eles estão afiados nisso, eles quase me deram uma aula: o que eu tenho que fazer pra não pegar Aids.

O aluno leva para sua vivência diária a aprendizagem, mas traz essa vivência pra cá.

-Um plano legal de complexidade é alcançado quando a gente, ou o aluno, consegue fazer esse ir e vir. Esse levar aquilo que estou aprendendo ali do conhecimento de livro, levar aquilo pra vida, ou trazer, porque a gente percebe, em alguns momentos, alguma dificuldade para estabelecer uma relação entre algo que estamos lendo com aquilo que acontece em sala de aula. Eu acho que, quando a gente consegue estabelecer esse ir e vir entre saberes cotidianos locais e saberes cotidianos escolares, esse currículo vivido com esse conhecimento científico, eu acho que a gente também se toca, é tocado, porque, quer queira, quer não, a gente também tem um momento de vivência, tem um processo de educação (Diálogo entre professores; Diário de campo, 09/03/2016).

Para Deleuze e Guattari (1996), a micropolítica não se distingue somente pelo tamanho, escala ou dimensão, mas pela natureza do sistema de referência considerado, de modo que o molecular instaurado na micropolítica não se define pela pequenez de seus elementos, mas pela natureza de sua "massa" - o fluxo de energia e de produção de processos de diferenciação e singularização que se compõe no encontro entre os corpos.

Desse modo, a base da concepção de cotidiano como micropolítica se fundamenta na complexidade e multiplicidade dos encontros dos corpos que, pelo conatus, ou seja, pelo esforço de perseverar na existência, buscam potencializar uma vida ativa e, portanto, ético-política (CARVALHO, 2012).

Não há espaço incolor ou neutro; há sempre uma composição de forças produzindo um espaço a cada instante, como demonstram as falas a seguir:

-A gente se constitui o tempo todo, então o processo vai à vida toda. A gente não se constitui na relação com o outro? Então, são essas relações conturbadas ou não que nos constituem.

-Às vezes, a gente está desassociando a realidade social do aluno do cotidiano escolar. Igual você falou: 'Porque você não usou uma música que é mais interessante pra ele?'. Se a gente for fazer só o que é interessante pra ele, por exemplo, só ouvem funk. Eu acho que a escola pode oportunizar novos mundos e mostrar também que ela sabe muita coisa do mundo dele, mas não existe só esse mundo; existem outros mundos. Mais importante ainda é ele concatenar esse mundo com outras possibilidades (Diálogo entre professores; Diário de campo, 09/03/2016).

Portanto, o espaço não é aprioristicamente dado, pois, uma vez criado, vem a ser a materialização das relações de forças produzidas em um instante. Sua duração é de um instante, porque no próximo a composição das forças já será outra. Podemos 
dizer, então, que, em cada escola, em cada casa, em cada bairro, em cada cidade, são infinitas as possibilidades de espaços, tanto quanto são infinitas as relações possíveis, ou seja, cada área é um espaço folheado de infinitas camadas possíveis que irão se atualizar a cada instante conforme a disputa das forças. "Existe igualmente, em cada instante de demarcação do aqui e agora, um folheado sincrônico de espaços heterogêneos" (GUATTARI, 1992, p. 153).

Assim sendo, a micropolítica constitui-se a partir do conceito de "espaço folheado", introduzido por Guattari (1992), de que não há espaço anterior às relações de força, logo não há um sujeito que concebe esse espaço, mas sim um conjunto de interferências, de forças que aumentam ou diminuem a potência umas das outras a cada composição.

A cada relação, portanto em toda relação de espaço, de saberes, de mídia, de sujeitos, há uma relação de poder. Este, então, não se configura como um poder central que somente submete as pessoas e as populações, pois ele está entre elas, nas práticas cotidianas de cada coletividade. Essa microfísica do poder atua no cotidiano, isto é, nas relações cotidianas como relações de poder, conforme se manifestou um professor:

\begin{abstract}
- Eu acho que falta espaço para o coletivo, sim, para discussão. Nós temos 200 dias letivos pra cumprir com o aluno. Então, se a gente tira tempo para planejar, para o sistema, é como se nós tivéssemos tirando carga horária do aluno. Quando a gente planeja, quando a gente tira esse tempo para o aluno, na verdade, nós estamos ganhando, pois nós estaremos devolvendo pra ele um trabalho futuro de muito maior qualidade. Só que, para garantir isso, a gente fica questionando: 'Ah, vamos fazer? E aí? E se alguém denunciar, se alguém falar?'. Se chegar alguém e disser: 'Ah, na minha escola a gente planeja'. 'Ah é? Como na minha a gente não planeja?'. Isso que a gente está fazendo é com pouquíssimo tempo. Então, muita coisa poderia ser muito melhor, muito mais bem feita, se tivesse o tempo e o espaço para o coletivo se constituir (Fala de um professor; Diário de campo, 06/04/2016).
\end{abstract}

Ao contrário de compreender o poder a partir de uma lógica de repressão, exclusão e censura, como comumente entendemos, Foucault (1987) nos propõe observar um poder que, antes de repressor, seja produtor. Um poder que micropoliticamente produz as maneiras de viver, os saberes, elege o que é importante, seleciona, avalia. Enfim, um poder produtor de realidades.

\title{
3 AFETOS E RELAÇÕES DE COMPOSIÇÃO
}

A microfísica é uma análise dessas relações de forças em que a intervenção do poder se dá ao nível do corpo, dos afetos, da forma potente ou impotente como saímos de cada relação. Ela analisa em cada espaço as forças com que esse espaço se agencia, o que significa o mesmo que analisar os afetos que são por ele disparados. Desse modo, a micropolítica trabalha o espaço como agente de forças, como "espaço folheado" que 
produz realidades. E esse é precisamente o poder do espaço situado no plano de imanência do cotidiano.

A subjetividade, para Guattari e Rolnik (1986, p. 32), “[...] não se situa no plano individual, seu campo é de todos os processos de produção social e material". Sendo assim, o termo subjetividade não significa a definição de sujeitos a partir de algo interior a eles, como um plano individual, pois os indivíduos são como terminais dessa subjetividade exterior, dessas relações de forças, como toda produção social e material. Corpos também inibem ou induzem ações.

Portanto, os corpos são como forças em relação com outras forças que irão afetar-se e modificar-se a cada relação. Os jeitos, os gestos, os espaços, a mídia, a linguagem são formas, mas são formas associadas a forças que estão em relações de poder - os terminais, de Guattari (1986). Os sujeitos e os espaços são terminais e estão sempre sendo afetados e afetando outras forças, estão sempre em movimento, fazendo-se e refazendo-se nessas relações, aumentando ou diminuindo seu poder. Por isso não há um sujeito, mas um processo que interferirá e será interferido incessantemente por forças plurais, ocasionalmente provenientes dos mesmos lugares, dos mesmos espaços. Enfim, desejamos chamar a atenção, para além da não existência de um sujeito e espaço fixado em uma essência, para o fato de que isso não significa, no entanto, que não possam ser produzidos como forma fixa, visto que a forma fixa também é uma produção resultante dessas forças plurais.

Espaços produzem corpos e corpos produzem "endereço", pois são forças ativas, mas são essas mesmas forças que atuam de forma inativa. Isso implica dizer que corpos e espaços se produzem como terminais de forças em relações de poder, ou seja, inseridos na possibilidade de serem forças ativas e inativas - são, portanto, fatos políticos. Toda produção de corpos dispara uma relação política e eles podem se constituir como forças ativas ou inativas.

Para Rolnik (2016), existem dois tipos de experiência que fazemos no mundo. A primeira é a experiência imediata, baseada na percepção que nos permite apreender as formas do mundo em seus contornos atuais - uma apreensão estruturada segundo a cartografia cultural vigente. Em outras palavras, quando vejo, escuto ou toco algo, minha experiência já vem associada ao repertório de representações que disponho e que, projetado sobre esse algo, atribui-lhe um sentido. Esse modo de cognição é indispensável para a existência em sociedade, porém essa é apenas uma dentre as múltiplas experiências que a subjetividade faz do mundo e que operam simultaneamente. Trata-se da experiência individual e/ou relativa, o que chamamos "sujeito". 
O outro tipo de experiência que Rolnik apresenta é a subjetividade que faz de seu entorno uma experiência das forças que agitam o mundo como corpo vivo e que produzem efeitos em nosso corpo em sua condição de vivente. Tais efeitos consistem em outra maneira de ver e de sentir aquilo que acontece em cada momento. Aqui já não se trata da experiência de um indivíduo, pois o mundo "vive" em nosso corpo e resiste de modo ativo à sujeição capitalística. O mundo que "vive" em nosso corpo coletivo irrompe com força no processo de enunciação estabelecido na conversação que segue:

\begin{abstract}
-Eu fui para um passeio com os alunos e tinha uma novata. Aí nós fomos descendo pra fazer a trilha de Itaúnas e eu deixei a máquina fotográfica e o celular dentro do ônibus. Na volta, não estavam mais. Dois alunos falaram: 'Professora, pode ficar despreocupada que daqui a meia hora seu celular vai estar com você'. Realmente, antes de 20 minutos, o aparelho apareceu dentro de uma lixeira próxima da escola onde nós estávamos. Um aluno falou assim: 'Foi fulana. Ela não é daqui da escola. Você quer que a gente faça o que com ela?'. Aí eu falei: 'Não, pelo amor de Deus, vocês não vão fazer nada com ela, o celular já está comigo, depois a gente conversa'.
\end{abstract}

-O que você está falando é que existe uma rede de comunicação muito eficiente entre eles?

-Antes de aparecer o celular, eles já me contaram quem o tinha apanhado.

-Na hora do recreio, nesse dia, eu estava lanchando, aí a aluna que havia furtado o celular entrou e uma menina gritou: 'A galera comanda a rede'. Imagina todas as crianças gritando, vaiando. Ela ficou assim, completamente humilhada. E eu falei: 'Gente, atire a primeira pedra quem nunca fez nada! Agir com violência contra ela vai resolver o quê? Vai trazer mais problema ainda. Vamos falar com ela pra ela não fazer mais isso. É aprender a lição e acabou'. Então você percebe que é uma rede mesmo... Foi uma coisa que eu fiquei chocada, eu tive que ir lá, porque pegaram a menina e quase a crucificaram.

-Não poderia aproveitar essa rede?

-Essa rede é uma rede de interesse. O que interessa a eles, o que convém a eles. Porém, aí a gente volta no mesmo problema: o que convém a eles? Acho que não tem ninguém que não está envolvido, por exemplo, na Mostra Cultural da escola, todos estão.

-Mas porque isso interessa a eles?

-Porque é uma atividade que faz pensar, ele está produzindo, ele está envolvido... (Diálogo entre a pesquisadora e um professor; Diário de campo, 27/04/2016)

Para Rolnik (2016), tanto as forças macropolíticas como as forças micropolíticas podem ser tanto progressistas como reativas e conservadoras. Ressalta, porém, que as forças colonial-capitalísticas que têm sido alçadas ou tomado o poder são macropoliticamente reacionárias e micropoliticamente reativas e conservadoras. Entretanto, é precisamente a gravidade dessa experiência que leva Rolnik a nos alertar que não basta atuar macropoliticamente, porque, por mais que se faça no plano macropolítico, por mais brilhante que sejam as ideias e as estratégias, do ponto de vista micropolítico reativo, o que se consegue é uma reacomodação do mapa vigente, na 
melhor das hipóteses, com um grau de desigualdade um pouco menor. E tudo volta para o mesmo lugar, visto que o que tende a funcionar, segundo uma micropolítica reativa, é a desconexão da experiência do fora-do-sujeito, reduzindo-se, assim, à do sujeito (postura individual).

Então, por não alcançar a experiência do fora-do-sujeito - na qual nos compomos dos efeitos do mundo em nosso corpo e são esses efeitos que nos indicam o que deve ser criado para que a vida coletiva volte a fluir - a experiência subjetiva é vivida e entendida como sendo do âmbito do indivíduo, movida por interesses individualistas (ROLNIK, 2016).

Para uma efetiva resistência a este mundo idealizado, podemos reconhecer mais claramente que é preciso deslocar-se tanto da macropolítica como da micropolítica dominante, ou seja, a micropolítica reativa do inconsciente colonial-capitalístico que comanda o sujeito moderno, pois referida a um tipo de resistência egoísta e centrado na luta pela sobrevivência, para caminharmos para uma micropolítica ativa de resistência (molecular). A fala abaixo caminha nesse sentido, ou seja, para além da reação individualista, vislumbra-se uma postura ativa e coletivamente orientada:

\begin{abstract}
-A gente reclama muito. Professor tem a mania de reclamar muito, reclama demais. Só fazem com a gente o que a gente permite que façam (inclusive aceitar essa droga de salário). $O$ aluno só vai até onde você permitir que ele vá. Como na sua casa, com seu marido, com seu filho, com seu irmão, com sua mãe. Se você se sente agredido, abusado, você fala: 'Você vai até aqui, parou aqui'. Quando a gente fala muito, a gente potencializa esse lado marginal da escola. Do mesmo jeito que tem esse aluno que vive essa realidade de arma, de crack, de droga, de arranhar carro do professor, têm outros que não têm e, se a gente der importância, isso vai realmente se tornar importante, os outros vão passar a dar valor para isso, e nós vamos virar reféns deles. E o professor tem um péssimo hábito de fazer isso, potencializar, valorizar, dar muita importância. Isso nós não podemos fazer, senão nos tornamos reféns. Há também a política do individualismo: 'Ah, eu não vou colocar meu corpo na frente', 'Eu não vou fazer nada'. Todo mundo recua, eles ganham força e acabou. Um único aluno consegue destruir uma escola inteira, e não pode. É o grupo, é a escola, o coletivo, os movimentos sociais, os professores, os pais e os alunos que vão transformar isso daí (Fala de uma professora; Diário de campo, 09/03/2016).
\end{abstract}

A micropolítica trata do campo das forças, do que é invisível, enquanto a macropolítica trata das formas, do que é visível. É justamente pelo fato de que esses modos são inseparáveis, que nos interessa a análise micropolítica, porque a educação e, especificamente, os cotidianos escolares costumam olhar somente para as formas, reduzindo o espaço à forma, como se nele apenas encontrássemos macropolítica.

A partir da ideia de que tudo é engendrado em uma relação de força, Deleuze e Guattari (1996) propõem uma micropolítica que devolva ao campo político cada ação, cada ato de produção de realidade. Esses atos nunca são fatos isolados, não são apenas formas, mas sempre estão engendrados em uma relação de poder, em uma relação de 
força. A micropolítica é um modo de recortar a realidade a partir do campo das forças, na medida em que essas também produzem realidades, afetos, desejos. A micropolítica nos permite analisar cada saber, cada corpo, cada endereço, cada objeto sob uma perspectiva de produção de realidade a partir das relações de poder.

\section{A MICROPOLÍTICA DO CORPO}

O capitalismo apresenta, dentre suas características, a transformação da vida em mercadoria e a captura das forças em fluxos dos corpos, impondo ao corpo uma intensa produção de percepções e desejos.

Assim sendo, torna-se, cada vez mais necessário, numa micropolítica do corpo, queenfatize a dimensão sensível e inacabada que é própria dos seres vivos. Como afirmam Guattari e Rolnik (1986, p. 127), “A questão micropolítica [...] diz respeito ao modo como se cruza o nível das diferenças sociais mais amplas (que chamarei de 'molar'), com aquele que chamarei de molecular". E prosseguem: "Parece difícil, mas é preciso simplesmente mudar a lógica [...] as lutas sociais são ao mesmo tempo, molares e moleculares" (p. 127).

Rolnik (2008) enfatiza que a ação micropolítica interfere na cartografia social dominante e na realidade sensível e, na maior parte das vezes, invisível, que é fruto da presença da alteridade, da capacidade de diferir que não cessa de afetar os nossos corpos.

A operação própria da ação macropolítica intervém nas tensões que se produzem na realidade visível, estratificada, entre polos em conflito na distribuição dos lugares estabelecidos pela cartografia dominante num dado contexto social (conflitos de classe, de raça, de etnia, de religião, de gênero etc.), como a conversação entre professores aponta:

\footnotetext{
-Até ele escolher qual mundo ele quer seguir... Eu faço parte deste, mas tem esse. Olha, tem esse aqui, esse aqui também é interessante.

-Mais importante é ele aprender a conviver com o mundo dele, ser ator do mundo dele. É como ela falou, é criar e produzir. Mas, pra ele criar e produzir, ele só vai ter condições quando ele passar a conhecer e dominar aquele mundo no qual ele vive, porque ele não o domina; ele só repete, ele só ouve, ele só reproduz. Então ele acha que ele é agente, mas ele é só receptor (Diálogo entre professores; Diário de campo, 06/04/2016).
}

A ação macropolítica inscreve-se no coração desses conflitos, num combate por uma redistribuição de agenciamentos e lugares, visando a uma configuração social mais justa. Já a operação própria à ação micropolítica intervém na tensão da dinâmica paradoxal entre, de um lado, a cartografia dominante com sua relativa estabilidade e, de outro, a realidade sensível em constante mudança, efeito da presença viva da diferença como campo de forças que não param de afetar nossos corpos e nos forçam a criar, de modo a dar expressividade à realidade sensível que pede passagem (ROLNIK, 
2008). Quando questionados sobre as atividades que seus alunos gostariam que a escola desenvolvesse, os professores assim enunciaram esses desejos:

\begin{abstract}
- Na escola deveria ter mais brincadeira; eles desejam aprender a tocar guitarra, bateria e música; todos adoram esportes; alguns querem aprender vôlei e basquete, porque gostam muito desses esportes; querem aprender natação; alguns desejam aprender basquete, porque são altos e/ou gostam desse esporte; futebol, vôlei, basquete e queimada; aprender a tocar instrumentos; eles desejam aprender mais coisas, como futebol e futsal; querem aprender futsal, teatro e produzir vídeo; já pediram para a escola oferecer espanhol, chinês, italiano e inglês; fazer esportes e artes; natação; muitas coisas, como natação; eles adoram artes. Muitos desejam aprender na escola a jogar futebol, vôlei, basquete. Acham que na escola podia ter natação e mais brincadeiras. Queriam que tivesse aula de instrumentos, como bateria, guitarra, música. Eles pedem para fazer teatro e produzir vídeo. Precisam aprender a ser obedientes e compartilhar mais as coisas com os outros. Alguns desejam aprender mais Matemática, Geografia, História. Desejam aprender a ler melhor (Falas de professores; Diário de campo, 04/05/ 2016).
\end{abstract}

São movimentos de reivindicação de professores por um cotidiano escolar com maior criação e resistência que se expressam em falas individualizadas, mas se inscrevem no plano coletivo que interfere nos modos cristalizados de estar no mundo, abrindo para outros mundos possíveis que, pelo encontro dos corpos, superam o individualismo (LAZZARATO, 2006). Porém não se trata de opor o individual ao coletivo, o corpo orgânico ao corpo sem órgão, mas construir um espaço de abertura intensiva a outros possíveis atuais e virtuais.

\title{
5 CONCLUINDO: POR UM DEVIR-AFETIVO...
}

Em um mundo cada vez mais marcado e atravessado pelas práticas de normalização dominante, produzir afetos e afecções alegres poderia ser uma das utopias possíveis de um corpo? Resistir poderia se apresentar, portanto, no contexto atual do capitalismo dominante, como a tomada de um corpo em sua utopia dos devires afetivos?

Para Deleuze e Guattari (1997), "devir" é um verbo com toda sua consistência. O movimento, o devir, é multiplicidade e singularidade, é por natureza imperceptível e se compõe de puras relações de velocidade e lentidão, de puros afetos que estão abaixo ou acima do limiar de percepção, percebidos apenas no plano de imanência.

Assim como Deleuze e Guattari, podemos dizer que tanto quanto cantar, compor, pintar, escrever, ao criar afetos, nosso objetivo é desencadear devires moleculares de toda espécie. Deixar-nos atravessar pelos fenômenos de limiar, pela temporalidade do acontecimento, transformarmo-nos uns nos outros por contágio. A imanência é o plano da existência, dos afetos, de uma vida na qual nos abrimos às 
intensidades, às forças de contágio do mundo, como um plano de imanência que se constitui como um plano de coexistências, em que os heterogêneos se compõem em uma multiplicidade de simbioses, em devires de passagem possibilitados pela experimentação, no caso, dos afetos alegres.

Assim, gostaríamos de afirmar o devir-alegria como possibilidade de o corpo resistir às suas normalizações na sociedade atual. A alegria, como prática de intensificação do sensível, possibilita a construção do plano de imanência do corpo: plano de experimentação corpórea aberta aos devires, num exercício ético de construção de si. Na medida em que a dimensão sensível é intensificada, o corpo pode entrar num exercício de escuta de si e de apropriação das forças que o atravessam e o fazem devir. A alegria pode possibilitar a tomada do corpo como jogo dinâmico entre uma dimensão intensiva e extensiva, multiplicando-o em formas cambiáveis.

Para Espinosa (apud DELEUZE; GUATTARI, 1997), não sabemos nada de um corpo enquanto não sabemos o que pode ele, isto é, quais são seus afetos, como eles podem ou não se compor com outros afetos, com os afetos de outro corpo, seja para destruílo, seja para ser destruído por ele, seja para trocar com esse outro corpo ações e paixões, seja para compor com ele um corpo mais potente. É preciso não comparar órgãos ou corpos individualizados, mas colocar elementos ou materiais numa relação que arranque o corpo da sua especificidade para fazê-lo devir outro, ou seja, resistir a uma macropolítica e a uma micropolítica reativa, saindo da passividade para a atividade, para a criação. As falas abaixo ilustram essa possibilidade de saída da passividade pela problematização:

- Gostaria de comentar que quem faz a escola não é o diretor, ou pelo menos não deveria ser. A escola deveria se sustentar na força do coletivo dos professores, dos pais, dos alunos, da comunidade. Na medida em que nós delegamos isso a uma pessoa, ela se torna síndica das nossas decisões. Isso não é uma relação horizontal; é extremamente vertical, e é uma visão que precisa ser modificada. Independentemente de qualquer pessoa que seja responsável pela direção, é importante ressaltar que o corpo coletivo é que deveria orientar a escola. Os princípios deveriam ser assumidos no coletivo.

-A escola vem de uma cultura vertical, em que as pessoas não estão muito acostumadas a isso. Já escutei comparações como: antigamente não era assim; essa gestão era assim. Então, temos essa dificuldade, podendo ser pelo costume de como a direção era vista, a ideia do poder que o diretor e a diretora têm. Na verdade, esse poder é de todo mundo! O diretor não pode gerir a escola sozinho (Conversa entre professores; Diário de campo, 09/03/2016).

A liberdade, portanto, não é o poder da vontade para extirpar os afetos, nem para escolher entre alternativas contrárias, mas a aptidão do corpo e da mente para o plural simultâneo (ESPINOSA, 1988). Assim, com Espinosa, ousamos dizer que são equivalentes os infinitos atos intelectuais, a civitas e a inteligência coletiva como modo de expressão coletiva. Segundo Espinosa, a massa, constituindo um sujeito único, cria 
um indivíduo coletivo cujo conatus é mais forte e superior do que o de cada um dos indivíduos isolados.

A noção de individualidade, então, deve ser substituída pela de individuação, pois toda individualidade é relativa, já que todo indivíduo é sempre composto de uma infinidade de partes extensivas que se definem por seu modo singular, mas, também, pelo seu determinismo exterior, sendo a autonomia a aptidão do corpo e da mente para o plural simultâneo e/ou para o coletivo (ESPINOSA, 2007). Considerando que o coletivo é mais que agrupamento ou círculo social, pois "[...] implica também a entrada de diversas coleções de objetos técnicos, de fluxos materiais e energéticos, de entidades incorporais, de idealidades matemáticas, estéticas, etc." (GUATTARI; ROLNIK, 1986, p. 319), tais comportamentos de busca de pertencimento podem ser considerados, também, como afetos/afecções.

Como vimos, a afecção de um corpo pode produzir aumento ou diminuição da potência de agir e, dessa forma, do ponto de vista dos afetos alegres e tristes (bons e maus encontros), remete a uma distinção entre paixões e ações, visto que as ações são baseadas não na servidão, mas na compreensão obtida pelas noções comuns e pela intuição intelectual. Portanto, razão, afecções e afetos estão intrinsecamente relacionados, pois, pelas afeç̧ões, podemos aumentar nosso grau de compreensão e, escapando das paixões e da alienação, produzir ações reflexivas sociais e comunitárias (constituição do comum). Vivemos de experimentações de encontros, ampliando as zonas de ativação de experiências alegres. Assim, como afirma Carvalho (2011, p. 111):

Essa 'arte do encontro', envolvendo a passagem do regime afetivo passivo a um ativo, tem como base a combinação de nossos encontros e/ou da composição dos corpos e, sendo assim, somente ao experienciarmos uma compreensão do funcionamento das redes interativas nas quais nossas relações se tecem e das quais dependem, atualizaremos nossa potência de agir.

É necessário, então, evitar a mutilação da alegria de aprender, do prazer de criar nas salas de aula das escolas e, nesse sentido, devemos explorar o cotidiano escolar como um "acontecimento" vivido nele mesmo. O currículo muda à medida que nos envolvemos com ele, refletimos sobre ele, consideramos sua complexidade tecida em rede de conversações e agimos em direção à sua realização, buscando, nos afetos e afecções, a potência inventiva de um cotidiano escolar não burocratizado e normalizado. Enfim, a ação dos indivíduos em relação visaria a uma construção coletiva na e pela qual eles procurariam, coletivamente, ser um vetor de produção de existência ativa e/ou do campo dos possíveis de liberação do potencial inventivo comum de construção de uma escola e/ou "[...] uma cidade como a do sonho". 
Eis o que se conta a respeito de sua

Fundação: homens de diferentes nações

Tiveram o mesmo sonho - viram uma

Mulher correr de noite, numa cidade

Desconhecida, de costas, com longos

Cabelos e nua. Sonharam que a

Perseguiam. Corriam de um lado para o

Outro, mas ela os despistava. Após o

Sonho partiram em busca daquela

Cidade; não a encontraram, mas

Encontraram uns aos outros; decidiram

Construir uma cidade como a do sonho.

(CALVINO, 1990)

\section{REFERÊNCIAS}

CALVINO, Ítalo. As cidades invisíveis. Tradução de Diogo Mainardi. São Paulo:

Companhia das Letras, 1990.

CARVALHO, Janete Magalhães. O cotidiano escolar como comunidade de afetos.

Petrópolis: DP et al., 2009.

CARVALHO, Janete Magalhães. A razão e os afetos na potencialização de bons encontros no currículo escolar: experiências cotidianas. In: FERRAÇO, Carlos Eduardo. (Org.). Currículo e educação básica: por entre redes de conhecimentos, imagens, narrativas, experiências e devires. Rio de Janeiro: Rovelle, 2011. v. 1, p. 103-121.

CARVALHO, Janete Magalhães. Espinosa: por um currículo político ético-afetivo no cotidiano escolar. In: FERRAÇO, Carlos Eduardo;GABRIEL, Carmem Teresa; AMORIM, Antonio Carlos (Org.). Teóricos e o campo do currículo. Campinas: Unicamp/ABEC/Abeu, 2012. v. 1, p. 120-140.

CARVALHO, Janete Magalhães. Currículo e formação de professores: devir-docência como afirmação da potência de aprendizagem em composições curriculares. Relatório de pesquisa. Vitória: CNPq, 2013-2016.

COUTO, Mia. Contos do nascer da terra. São Paulo: Companhia das Letras. 2014.

DELEUZE, G. Diferença e repetição. Rio de Janeiro: Graal, 1988.

DELEUZE, Gilles; GUATTARI, Félix. Micropolítica e segmentaridade. Tradução de Suely Rolnik. In: DELEUZE, Gilles; GUATTARI, Félix. Mil platôs: capitalismo e esquizofrenia. Rio de Janeiro: Editora 34, 1996.

DELEUZE, Gilles; GUATTARI, Félix. Devir-intenso, devir-animal, devir-imperceptível. Tradução de Suely Rolnik. In: DELEUZE, Gilles; GUATTARI, Félix. Mil platôs: capitalismo e esquizofrenia. Rio de Janeiro: Editora 34, 1997. 
DELEUZE, Gilles; PARNET, Claire. Diálogos. Tradução de José Gabriel Cunha. Lisboa: Relógio D’Água Editores, 2004.

ESCOSSIA, Liliana da; KASTRUP, Virginia. O conceito de coletivo como superação da dicotomia indivíduo-sociedade. Psicologia em Estudo, Maringá, v. 10, n. 2, p. 295-304, maio/ago. 2005.

ESPINOSA, Benedito. Tratado teológico-político. Tradução de Diogo Pires Aurélio. Lisboa: Imprensa Nacional - Casa da Moeda, 1988.

ESPINOSA, Benedito de. Ética. Tradução de Tomaz Tadeu. Belo Horizonte: Autêntica, 2007.

FOUCAULT, Michel de. Vigiar e punir. Tradução de Raquel Ramalhete. Petrópolis: Vozes, 1987.

GUATTARI, Félix. Caosmose: um novo paradigma estético. Tradução de Ana Lúcia de Oliveira e Lúcia Cláudia Leão. São Paulo: Editora 34, 1992.

GUATTARI, Félix; ROLNIK, Suely. Micropolítica: cartografias do desejo. Petrópolis: Vozes, 1986.

FOUCAULT, Michel. Vigiar e punir: nascimento da prisão. Tradução de Raquel Ramalhete. Petrópolis: Vozes, 1987.

LAZZARATO, Maurizio. As revoluções do capitalismo. Rio de Janeiro: Civilização Brasileira, 2006.

ROLNIK, Suely. Desentranhando futuros. ComCiência, Campinas, n. 99, p. 1-5, 2008.

ROLNIK, Suely. A hora da micropolítica. São Paulo: n-1 Edições, 2016. (Série Pandemia).

SARAMAGO, José. Évora: patrimônio da humanidade. Évora: Litografia Tejo, 1997.

Revisão gramatical do texto sob responsabilidade de:

Alina da Silva Bonella

Registro no MEC: 10.077

E-mail: alinabonella@yahoo.com.br . 